\title{
AN ASSESSMENT OF PROJECT MONITORING PRACTICES ON CONSTRUCTION SITES IN ABUJA NIGERIA
}

\section{Nkeleme Ifeanyichukwu Emmanuel ${ }^{1}$}

Department of Building

Federal University of Technology Owerri- Imo State Bishopeio@Yahoo.Com/ emmanuel.nkeleme@Futo.edu.ng

Offiong Bassey Effiong

Ahmadu Bello University Zaria effmsc2294@gmail/com

\section{Chukwudi Stanley Ozoh}

Department of Architecture

Federal University of Technology Owerri- Imo State

-

Chukwudi.ozoh@futo.edu.ng

\section{Ukwunna Chidi}

Department of Architecture

Federal University of Technology Owerri- Imo State bbujo0718@yahoo.com

\section{Osadola Opeyemi Ayodeji}

Department of Building

Federal University of Technology Owerri- Imo State

Opechi4real@gmail.com

DOI: 10.26821/IJSHRE.9.6.2021.9606

\begin{abstract}
Monitoring is critical to all projects. It is a necessary core management instrument, both for projects that might be encountering problems and for projects which are encountering particular success. Thus, adequate project monitoring is a prime requirement for project delivery. This research assessed the project monitoring practices Nkeleme Ifeanyichukwu Emmanuel; Offiong Bassey Effiong; Chukwudi Stanley Ozoh; Ukwunna Chidi;


used in executing projects in Abuja with a view of: examining the project monitoring methods used in executing construction projects; assess the relative effectiveness of these methods in project delivery. It was affected, by means of literature review and field survey entailing the use of a well structured questionnaire and a checklist. A total of a hundred and fifty (150) questionnaires were distributed with a percentage response of $84.7 \%(127$ returned). The result of the analysis revealed that: Project monitoring processes of most firms in the study area are mainly manually oriented and rarely have their monitoring done with adequate work breakdown process. Correct application of specified technique is one of the monitoring processes that are rarely ensured; there is less emphasis on monitoring on the various construction stages during construction. Thus, it is recommended that: monitoring should be computer oriented for easy information handling, communication within monitoring personals and for adequate record management; the selection of the work breakdown basis should consider the peculiarities of the project under consideration; client related factors, and Project Manager related factor in the generation of the monitoring strategy for each project.

\section{Key Words: Project Monitoring, Construction site, Project Delivery}

\section{INTRODUCTION}

A project is a series of activities that aim at solving particular problems within a given time frame and in a particular location (Clifford \& Richard, 2004). Th ose is to eonvert a set of resources, money, men, materials and machines into desired results through a set of activities or process (Bhavesh, 2006).

In a project, plans are usually drawn to ensure that work is carried out to the desired quality, in the allowed time and according to budget (Harrison, 1996). These parameters quality, cost and time are critical and should therefore be monitored as they define the success level of any construction project (Bamisile, 2004).

The monitoring of quality is effective when it is measured against standard. The project quality management plan serves as a standard against which the quality of a construction can be measured against. The monitoring of quality should embrace all aspects by which a construction project is judged including spatial arrangement, circulation, efficiency, aesthetic(s), flexibility as well as its functional ability as a climate modifier and as a suitable structure. For control and monitoring purposes, the detailed cost estimate should be converted to a project budget, and the project budget is used subsequently as a guide for management (Duncan, 2010).

According to Pinto \& Trailer, (1999) the success of the project is determined by the effective implementation of the management of the project cost. Hence managing cost with the scope of time would provide good project outcome (Melton, 2008).

According to CORBON, (2010) construction typically involves a deadline for work completion, so builders must pay attention to time, the Builder's Construction Programmes, the tool for monitoring the construction time. The duration of activities must therefore be monitored and compared to expected durations so that the project is completed within the time required.

Divergences from the plan however occur and within construction such occurrences are common. Such divergences are nevertheless expected because of the nature of construction work and the uncertainties 
associated with it (Harrison, 1996). In the case where the differences between the plan and the actual work performance are large, control action is normally required to bring the actual performance on course with the desired state of the plan (Harrison, 1996).

Arditi (1998), Mauricio and Carlos (2002) confirmed that the performance of companies in project delivery depends largely on their control structures as well as their production planning. Planning defines the strategies, tactics and methods for achieving project objectives, while monitoring and control provide the required checks and balances for ensuring that the plans and overall project objectives are achieved.

Kharbanda and Pinto (1996) maintained that most, if not all, major project failures could be traced to inadequate and inaccurate planning or blind adherence to the originally formulated plans regardless of how the environment changed in the interim. In construction, contractors are one of the major parties concerned with the monitoring and control of projects. They are responsible for executing the works that form the contract.

Monitoring is the systematic collection and analysis of information as a project progresses. It is aimed at improving the efficiency and effectiveness of a project. It consist of those processes performed to observe project execution so that potential problems can be identified in a timely manner and corrective action can be taken when necessary, to control the execution of the project. The key benefit is that project performance is observed and measured regularly to identify variances from the project management plan (Lock, 1996).

Monitoring also means to keep a careful check of project activities over a period of time. To work to its full potential any project needs to set out proposals and objectives. Then a monitoring system should be worked out to keep a check on all the activities including finance. This will help project team to know how things are going, as well as giving early warning of possible problems and difficulties (Duncan, 2010).

According to Duncan (2010) project plan should establish mile stones that can be monitored for completion or deviation. As the project is implemented, it is important to monitor and control progress based on the objectives that were established in the project plan. It may also be necessary to make adjustments to address unforeseen challenges, obstacles and opportunities as they arise.

\section{Research Methodology}

This research was pursued through a field work. The Field work entail the use of the questionnaire as well as the interview of the respondents to establish their opinion on the effectiveness of the Project monitoring Technique adopted by the construction firms operating within the area of study. A checklist adopted in accordance to the NIOB Project monitoring template was also used.

\section{The Study Area}

The research was conducted in Abuja because it is one the fastest developing cities in the world and the activities of construction is highly noticeable. The city of Abuja has a population of 776,298, making it one of the top ten most populous cities in Nigeria. Abuja has witnessed a huge influx of people into the city which has 
led to the emergence of satellites towns such as Karu Urban Area, Suleja urban area, Lugbe, Kuje, Gwagwalada and other smaller settlement in which the planned city is sprawling towards.

The study was conducted among public construction sites, the sites were mainly construction sites. The construction type includes buildings, roads and drainage construction. The categories of construction workers the researcher administered the questionnaire are the construction project team.

\section{The Field Work Of The Research}

The field work of this research was conducted using various research instruments, each adopted to meet a particular research need. The various instruments and its application are as explained:

\section{Tools for Data Collection.}

In addition to the literature review other data collection instruments such as a well-structured questionnaire was also adopted. A checklist was also employed. The details of the sample size and the sampling method using the field survey are given:

\section{Sample Size and Sampling Techniques}

With regards to the sampling size in the distribution of the questionnaire, the sampling size will be determined based on the formula below considering the fact that the targeted population is unknown

\section{$\mathbf{n}=\left(\mathbf{z}^{2} \mathbf{p q}\right) / \mathbf{d}^{2}$}

where: $\quad \mathrm{n}=$ the desired sample size

$\mathrm{z}=$ the ordinate on the Normal curve corresponding to $\alpha$ or the standard normal deviate, usually any of the following determined based on the 'margin error formula'

i. A $95 \%$ level of confidence has $\alpha=0.05$ and critical value of $z_{\alpha / 2}=1.96$.

$\mathrm{P}=$ the proportion in the target population estimated to have particular characteristic (normal between the range of $0.1-0.5$ )

$$
\mathrm{q}=1.0-\mathrm{p}
$$

$\mathrm{d}=$ degree of accuracy corresponding to the confidence level and $\mathrm{Z}$ selected.

For the purpose of this study, a confidence level of $95 \%$ was adopted.

Consequently, the sample size is determined as thus, $(z=1.96, d=0.05$ where $p=0.9, q=0.1)$

$\mathbf{N}=\left(1.96^{2} \mathrm{X} 0.9 \mathrm{X} 0.1\right) /(0.05)^{2}=138$

Therefore a total of hundred and fifty project team members (respondents) were sampled in the area. The sampling technique to be adopted in the distribution of the questionnaires was done using random sampling technique. 


\section{Data Analysis}

The data collected for this study was subjected to various statistical analyses using the computer based software "Statistical Package of Social Sciences" (SPSS). The results of the analysis are presented in the forms of table for the purpose of easy comparism and clear expression of the findings. Relative importance indices (RII) were also used to rank Areas of Emphasis during Project Monitoring.

\section{Data Presentation, Analysis and Discussion}

\section{Percentage Response}

A total of one hundred and fifty questionnaires were administered to those that are responsible for monitoring within the area of study. The percentages of responses are presented in Table 4.1. Form the Table it can be gathered that a total of one hundred and twenty-seven questions were received adequately filled giving a percentage response of $84.7 \%$.

\section{Table1 Questionnaire Administered}

\begin{tabular}{lcc}
\hline Questionnaires & Percentage of (\%) \\
\hline Number returned & Frequency & 84.7 \\
Numbers not returned & 150 & 10.3 \\
\hline Total & 0
\end{tabular}

Source: Field Survey, (2015)

\section{Respondents Profile}

From the result of the analysis of the respondents opinion conducted, the profile of the respondents is presented in Table.2. It can be observed that a greater percentage of the respondent were Builders $(41.7 \%)$ followed closely by Quantity Surveyors (23.6\%) and then the architects (21.3\%).

With regard to the academic qualification of the respondents it can be seen that a larger percentage of the respondents were degree holders $(48.8 \%)$ with very few masters holders corresponding to just $9.5 \%$ of the respondent.

With respect to the kind of work the firms engage in, it can be noted that the largest percentage of respondents engaged in building construction ( $50.0 \%$ ), followed by estate development (29.1\%) and lastly by road construction $(6.3 \%)$ of the respondents. It was also observed that a larger percentage of the respondent were Middle Level staff $(55.1 \%)$ in their firm, followed by those in the top level $(23.6 \%)$ and the last is those at the low level $(21.3 \%)$. 
Table 2 Respondents Profile

\begin{tabular}{|c|c|c|c|c|}
\hline $\mathbf{S} / \mathbf{N}$ & Variable & Option & $\begin{array}{c}\text { Frequency } \\
\text { (No) }\end{array}$ & $\begin{array}{c}\text { Percentage } \\
(\%)\end{array}$ \\
\hline \multirow[t]{6}{*}{$\mathbf{1}$} & Profession : & a) Building & 53 & 41.7 \\
\hline & & b) Architecture & 27 & 21.3 \\
\hline & & c) Engineering (Structural) & 17 & 13.4 \\
\hline & & d) Quantity Surveying & 30 & 23.6 \\
\hline & & e) Others & - & - \\
\hline & \multicolumn{2}{|r|}{ Total } & 127 & 100 \\
\hline \multirow[t]{7}{*}{2} & Highest Qualification & a) Ordinary National Diploma (OND) & - & - \\
\hline & & b) Higher National Diploma (HND) & 17 & 13.4 \\
\hline & & c) Bachelor's Degree & 62 & 48.8 \\
\hline & & d) Post-Gradua & 36 & 28.3 \\
\hline & & e) Masters & 12 & 9.5 \\
\hline & & f) Doct & - & - \\
\hline & & Total & 127 & 100 \\
\hline \multirow[t]{5}{*}{3} & Kind of work firms engage in & nstruction & 8 & 6.3 \\
\hline & & astruction & 52 & 50.0 \\
\hline & & c) Estate development & 37 & 29.1 \\
\hline & & d) Design Consultancy & 30 & 23.6 \\
\hline & & Total & 127 & 100 \\
\hline \multirow[t]{4}{*}{4} & Respondents level in the firm & a) Top level & 30 & 23.6 \\
\hline & & b) Middle level & 70 & 55.1 \\
\hline & & c) Low level & 27 & 21.3 \\
\hline & & Total & 127 & 100 \\
\hline
\end{tabular}

Source: Field Survey, (2015) 


\section{Monitoring Process During Project Execution}

Table 3 Project Monitoring Process

\begin{tabular}{|c|c|c|c|c|}
\hline $\mathbf{S} / \mathbf{N}$ & Variable & Option & Frequency & $\begin{array}{c}\text { Percentage } \\
(\%)\end{array}$ \\
\hline \multirow[t]{4}{*}{$\mathbf{1}$} & Company Monitoring Process & a) By Out Sourcing & 32 & 25.2 \\
\hline & & b) Use of IN-house monitoring & 54 & 42.5 \\
\hline & & $\begin{array}{l}\text { c) Combination of 'a;' and 'b' } \\
\text { above }\end{array}$ & 41 & 32.3 \\
\hline & & Total & 127 & 100 \\
\hline \multirow[t]{5}{*}{2} & Monitoring Method Adopted & a) Manually Oriented & 65 & 51.2 \\
\hline & & b) Computer base Oriented & 32 & 25.2 \\
\hline & & c) Combination of manual and & 30 & 23.6 \\
\hline & & Computer base & & \\
\hline & & Total & 127 & 100 \\
\hline \multirow[t]{4}{*}{3} & Breakdown of the Construction & a) Yes & 17 & 13.4 \\
\hline & Process into units for adequate & b) No & 72 & 56.7 \\
\hline & monitoring & c) Unknown & 18 & 14.2 \\
\hline & & Total & 127 & 100 \\
\hline
\end{tabular}

Source: Field Survey, (2015)

From Table 3, it can be observed that majority of the respondents noted that the bulk of the company monitoring process was done using $\mathrm{In}_{\odot}$ housing (42.5\%), followed closely by a combination of out sourcing and in housing (32.3\%). With regards to the Monitoring methods adopted, 51.2\% of the respondents was of the view that the monitoring method adopted are manually oriented, whereas $25.2 \%$ of the respondent suggested that the monitoring method were system oriented. Similarly, it can be gathered from the responses that $56.7 \%$ of the respondent attested to the fact that there is no Breakdown of the Construction Process into units for adequate monitoring; whereas only $13.4 \%$ of the respondent who noted that construction process are broken into units for adequate monitoring process.

Table 4: Ranking of the Basis of Breakdown of Construction Work

\begin{tabular}{lccccccccccccc}
\hline & \multicolumn{1}{c}{ WEIGHTNG/RESPONSE FREQUENCY } & & & \\
Basis & $\mathbf{1}$ & $\mathbf{2}$ & $\mathbf{3}$ & $\mathbf{4}$ & $\mathbf{5}$ & $\left(\sum \mathbf{f}\right)$ & $\sum \mathbf{f x}$ & MEANI & SD & RII & RANK \\
\hline Stages of construction activities & - & - & - & 107 & 20 & 127 & 528 & 4.16 & 4.230 & 0.83 & $1^{\text {st }}$ \\
Traits involved in construction & - & - & 11 & 116 & - & 127 & 497 & 3.91 & 4.224 & 0.78 & $4^{\text {th }}$ \\
Team structure & - & -07 & - & 116 & 04 & 127 & 498 & 3.92 & 4.223 & 0.79 & $3^{\text {rd }}$ \\
Outcomes/deliverables of project & - & - & - & 71 & 35 & 127 & 501 & 3.94 & 4.228 & 0.80 & $2^{\text {nd }}$ \\
\hline
\end{tabular}

Source: Field Survey, (2015)

Where: 1- never used, 2- seldom used, 3-undecisive, 4-usually used, 5- Always used 
From Table 4. it can be gathered that the respondent suggestion of the most effectively used basis of breakdown of construction work for monitoring purpose is based on the Stage of construction activities (RII: 0.83); this is followed closely by breakdown on the basis of the outcomes/ deliverables of project (RII: 0.80). However based on the Relative Importance Index of the breakdown measures identified (above 0.6), all the identified measures are appropriate.

\section{Commonly Used Project Monitoring Technique}

The opinion of the respondents was also sought regarding Project monitoring techniques. Table 5 presents the respondents ranking of the extent of use of the various monitoring techniques. From the Table it can e established that the most frequently used monitoring technique is Programme Evaluation and Review Technique $(\mathrm{RII}=0.86)$, followed closely by Gantt chart $(\mathrm{RII}=0.81)$. However, the lease used Project monitoring technique as opined by the respondent is Progress Curve $(\mathrm{RII}=0.63)$.

Table 5: Ranking Of the Project Monitoring Technique and Performance Measurement Tool Source: Field Survey, (2014)

\section{WEIGHTNG/RESPONSE FREQUENCY}

\begin{tabular}{|c|c|c|c|c|c|c|c|c|c|c|}
\hline Monitoring Techniques & 1 & 2 & 3 & & & $\left(\sum \mathbf{f}\right)$ & $\sum \mathbf{f x}$ & MEAN & RII & RANK \\
\hline Gantt chart & - & 04 & & & 7 & 127 & 512 & 4.03 & 0.81 & $2^{\text {nd }}$ \\
\hline Critical Path Method (CPM) Network & - & & & & 16 & 127 & 505 & 3.98 & 0.80 & $3^{\text {rd }}$ \\
\hline Diagram & & & & & & & & & & \\
\hline Programme Evaluation and Review & & & - & 91 & 36 & 127 & 544 & 4.28 & 0.86 & $1^{\mathrm{st}}$ \\
\hline Technique & & & & & & & & & & \\
\hline Line of Balance & - & 03 & 53 & 44 & 27 & 127 & 476 & 3.74 & 0.75 & $4^{\text {th }}$ \\
\hline Progress Curve & 13 & 17 & 41 & 51 & 05 & 127 & 399 & 3.14 & 0.63 & $5^{\text {th }}$ \\
\hline
\end{tabular}

Where: 1- never used, 2- seldom used, 3-undecisive, 4-usually used, 5- Always used

\section{The Impact of Adequate Monitoring On Effective Project Delivery}

The ranking of the impact of adequate monitoring process in fostering effective Project Delivery as opined by the respondents is presented in Table 6. It can be established that one of the impact of adequate monitoring include: achieve the project delivered to specified quality (RII=0.87), followed closely by achieving project delivery at predetermined time $(\mathrm{RII}=0.85)$. Other benefits or impact of adequate monitoring in project delivery is as shown. 


\section{WEIGHTNG/RESPONSE FREQUENCY}

\begin{tabular}{llllllllllll} 
Benefits & $\mathbf{1}$ & $\mathbf{2}$ & $\mathbf{3}$ & $\mathbf{4}$ & $\mathbf{5}$ & $\left(\sum \mathbf{f}\right)$ & $\sum \mathbf{f x}$ & $\mathbf{M E A N}$ & SD & RII & RANK \\
\hline Helps to achieve project delivery at & - & - & 05 & 88 & 34 & 127 & 537 & 4.23 & 4.232 & 0.85 & $2^{\text {nd }}$
\end{tabular}
predetermined time

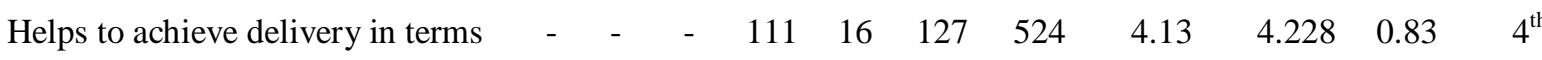
of the scope of work

$\begin{array}{lllllllllllll}\text { Achieve the project delivered to } & - & - & - & 85 & 42 & 127 & 550 & 4.33 & 4.233 & 0.87 & 1^{\text {st }}\end{array}$
specified quality

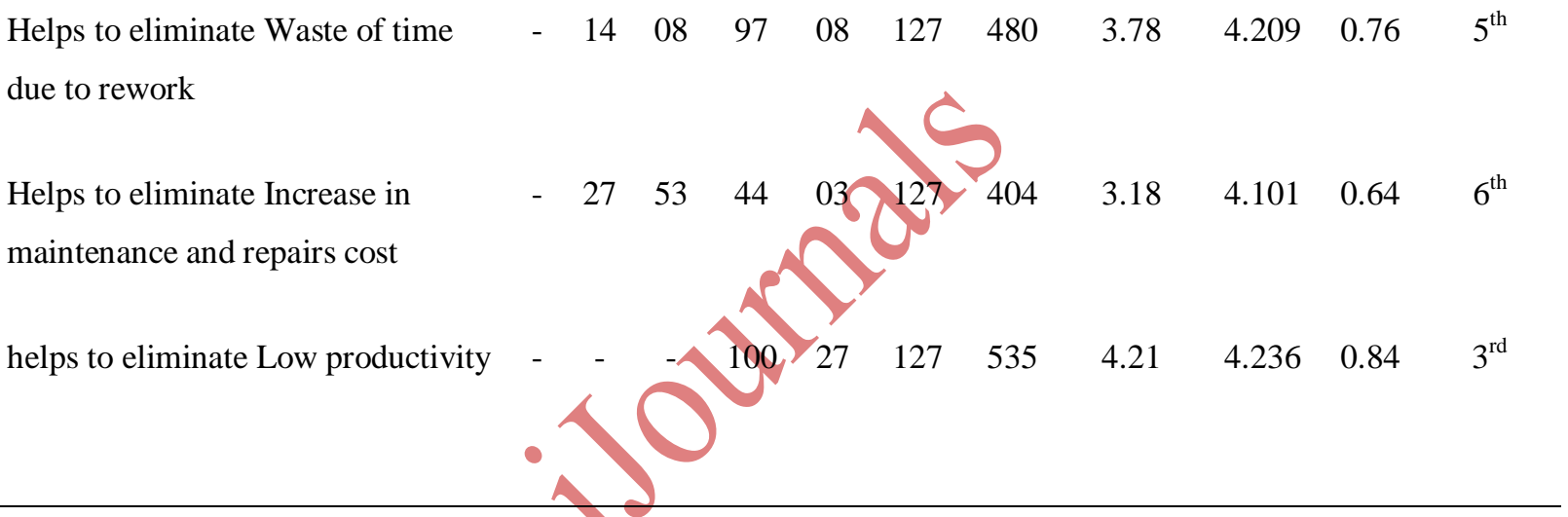

Source: Field Survey, (2015)

Where: 1- no impact, 2- slight impact, 3-undecisdede, 4-large impact, 5- very large impact

\section{Checklist Survey}

The result of the checklist survey conducted is presented in Table 7. It can be established that most of the construction firms rarely consider client related factors in the generation of their monitoring practices; similarly the project manager related factors are often ignored as most of the facts sort via the checklist were actually not considered. However, the result revealed that most of the firms give more consideration to contractor related factor in their monitoring practices. 
Table 7: Result of the Checklist Survey

\begin{tabular}{|c|c|c|c|c|c|}
\hline $\mathbf{S} / \mathbf{N}$ & Variable & & Option & Remark & Exceptions \\
\hline \multirow[t]{10}{*}{1} & PROJECT & a) & Communication system & Not & None \\
\hline & MANAGEMENT & & & Considered & \\
\hline & FACTORS & b) & Planning effort & Considered & None \\
\hline & & c) & $\begin{array}{l}\text { Implementing an effective quality } \\
\text { assurance program }\end{array}$ & Considered & None \\
\hline & & d) & Risk identification and allocation & Considered & Few \\
\hline & & e) & Overall managerial actions & Considered & \\
\hline & & f) & Control of sub-contractors' work & Not & Few \\
\hline & & & & Considered & \\
\hline & & g) & Formal dispute resolution process & Considered & None \\
\hline & & h) & Decision making effectiveness & Considered & None \\
\hline \multirow[t]{9}{*}{2} & CLIENT RELATED & a) & Client's ability to brief & Not & Few \\
\hline & FACTORS & & & Considered & \\
\hline & & b) & Cliont', & Not & None \\
\hline & & & & Considered & \\
\hline & & c) & Timely decision by owner/ owner's & Not & Few \\
\hline & & & & Considered & \\
\hline & & $\mathrm{d}$ & w construction & Not & None \\
\hline & & & cost & satisfactory & \\
\hline & & e) & Client's ability to make decision & Absent & None \\
\hline \multirow[t]{6}{*}{3} & DESIGN TEAM- & a) & Design team experience & Not & None \\
\hline & RELATED FACTORS: & & & Considered & \\
\hline & & b) & Project design complexity & Not & None \\
\hline & & & & Considered & \\
\hline & & c) & Mistakes/ delays in producing design & Not & None \\
\hline & & & documents & Considered & \\
\hline \multirow[t]{4}{*}{4} & CONTRACTOR- & a) & Site management & Considered & None \\
\hline & KELA TED FAC TOKS: & b) & Extent (Involvement) of & Considered & None \\
\hline & & & Subcontracting & & \\
\hline & & c) & Effectiveness of cost control system & Considered & Few \\
\hline
\end{tabular}


ISSN-2347-4890

Volume 9 Issue 6 June 2021

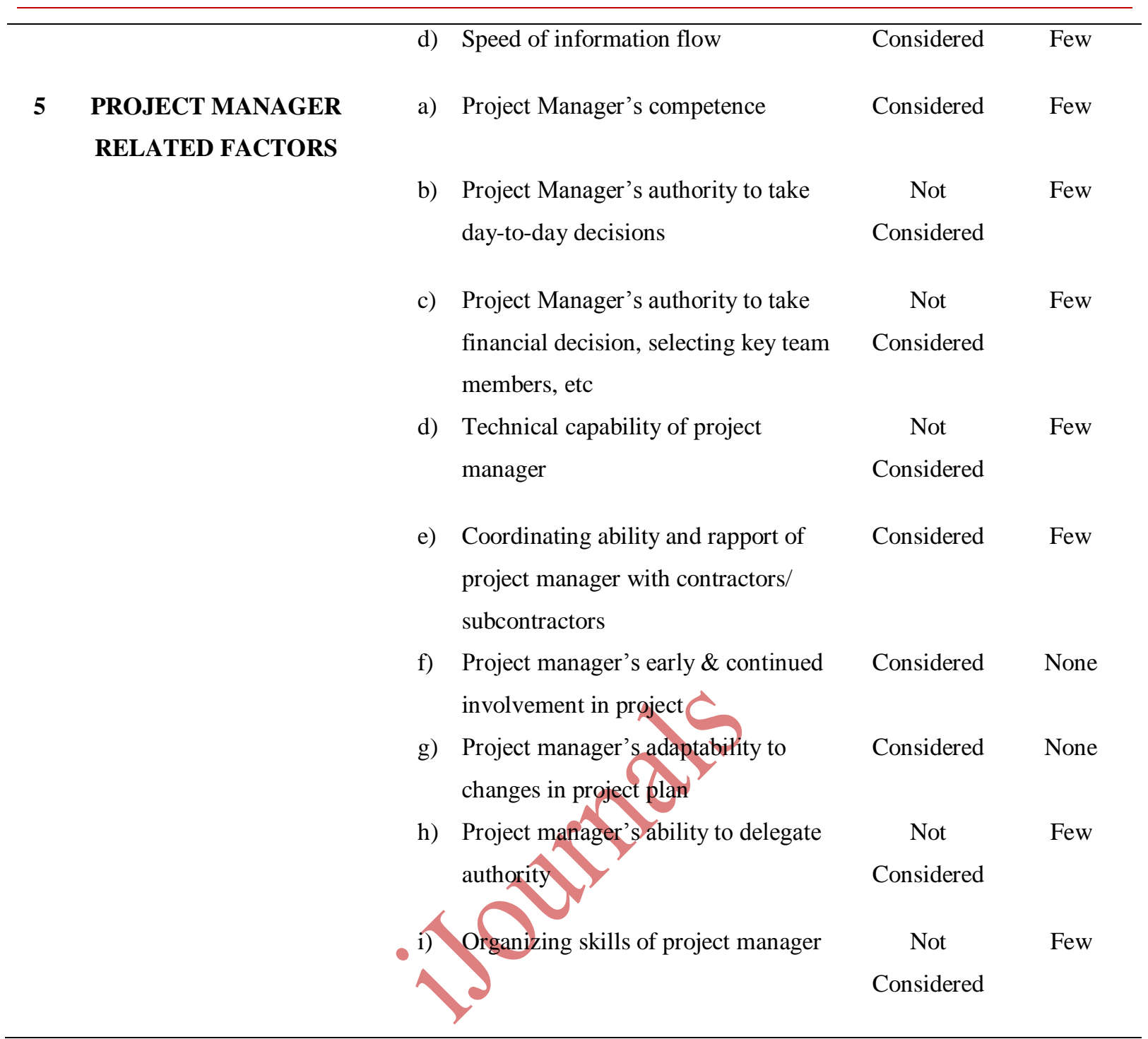

\section{Source: Field Survey, (2015)}

Summary, Conclusion and Recommendation

Summary:

The following are the summary of the findings:

a) The respondents were more of builders (41.7\%) that other professional: architects (21.3\%), Engineers $(13.4 \%)$ and Surveyors $(23.6 \%)$

b) A larger percentage of construction professional/respondents had their highest qualification as Bachelor's Degree (48.8\%) and then very few with a Post graduate diploma (28.3\%).

c) Construction firm engage mostly in building construction (50.0\%), others in Estate development (29.1\%) and very few in Design consultancy (23.6\%) 
d) Monitoring methods commonly adopted are manually oriented (51.2\%). Similarly work breakdown of the construction into units for adequate monitoring are seldom done as noted by the respondents $(56.7 \%)$

e) The most effectively used measure of breakdown of construction work for monitoring purpose is basis of the Stage of construction activities (RII: 0.83).

f) Programme Evaluation and Review Technique (RII:0.86) identified as the predominant project monitoring technique and performance measurement tool used by construction firms in Abuja

g) Regarding the benefits of adequate monitoring; achieving the project delivered to specified quality $(\mathrm{RII}=0.87)$; and achieving project delivery at predetermined time $(\mathrm{RII}=0.85)$ are some of the major benefits of adequate monitoring in project delivery.

h) From the Checlist it can be established that Clients related Factors are seldomly considered in the monitoring process of most projects.

\subsection{CONCLUSION}

Based on the findings, the following conclusions can be drawn

The monitoring processes of most firms in the study area are mainly manually oriented and rarely have their monitoring done with adequate work breakdown process. Similarly the monitoring process is mostly done via in-house monitoring.

Correct application of specified technique is one of the monitoring processes that is rarely ensured. However, other monitoring process like; keeping dairy of event, filing of instruction received have being identified as monitoring practices that are commonly done by most firms

Finally, Construction firms rarely consider client related factors in the generation of their monitoring practices; similarly the project manager related factors are often ignored. However, the result revealed that most of the firms give more consideration to contractor related factor in their monitoring practices

\subsection{RECOMMENDATION}

The following are recommended:

i. Pre-Project monitoring process like; ensuring that all assumptions during the pre-tender planning and the construction method chosen are documented, declaration of targeted cost before the commencement of work at each stage, should never be neglected as it can jeopardise the entire monitoring process.

ii. Monitoring process can be improved if it is made computer oriented for easy information handling, communication within monitoring personals and for adequate record management. 
iii. Construction work breakdown should be adequately done so as facilitate effective monitoring process and the selection of the work breakdown basis should consider the peculiarities of the project under consideration.

iv. Adequate consideration should be given to client related factors, as well as Project Manager related factor in the generation of the monitoring strategy for each project. In line with this, it suggested that the monitoring strategy should take into consideration the peculiarities project as no two projects are exactly the same.

\section{REFERENCES}

Arditi, J.D. (1988). Construction Productivity Improvement. Journal of the Construction Dividon (ASCE), 111(1). pp. $1-4$

Bamisile, A. (2004). Building Production Management, Foresight Press Limited, Lagos, Nigeria.

Bhavesh, M. P (2006). Project Management (Strategy, Financial Planning, Evaluation and Control) PTV Ltd, New Delhi.

Council of Registered Builders of Nigeria (2010). Monitoring Manual for Builders, Builders document 05/CORBON/2010.

Duncan H. (2010). Project planning, A Step by Step Guide, PMP. ProjectSmart.co.uk

Harrison, F. (1996). Advanced Project Management, A Structured Approach, $3^{\text {rd }}$ Edition, Grower publishing, U.K.

Harris Fran \& McCaffer, R. (2001). Modern Construction Management $5^{\text {th }}$ Edition, Blackwell Publishing Company. Pg.151, 160162.

Kharbanda, O.P. and Pinto, J.K. (1996). What Made Gente Gallop! Learning from Project Failures. $1^{\text {st }}$ Edition. Newyork. VonNostrand Reinhold.

Lock, Dennis (1996). The Essentials of Project Management. Cover Publishing Ltd, Hampshire, England. Mauricio, M.S.B and Carlos, T.F. (2002). Contribution to the Evaluation of Production Planning and Control System in Building Companies Proceedings: IGL Conference. Granado, Brazil, 12 August.

Melton, Trish. (2008). Developing a Project Delivery Strategy. Real Project Planning. Elsevier, Ltd.

Pinto, J. K. \& Trailer, J.W. (1999). Essentials of Project Control. Pennsylvania, USA:

Project Management Institute, Inc. 